\title{
Uso do fonolito e bactérias solubilizadoras de potássio na cultura do feijoeiro
}

\author{
Use of phonolite and potassium-solubilizing bacteria in bean crops \\ Uso de fonolita y bacterias solubilizadoras de potasio en cultivos de frijol
}

Recebido: 27/01/2022 | Revisado: 01/02/2022 | Aceito: 02/02/2022 | Publicado: 05/02/2022

\author{
Sérgio Diogo de Pádua \\ ORCID: https://orcid.org/0000-0002-2953-0721 \\ Universidade José do Rosário Vellano, Brasil \\ E-mail: sdpadua@gmail.com \\ Ligiane Aparecida Florentino \\ ORCID: https://orcid.org/0000-0001-9092-3017 \\ Universidade José do Rosário Vellano, Brasil \\ E-mail: ligiane.florentino@unifenas.br
}

\begin{abstract}
Resumo
Objetivou-se com esse estudo analisar o uso do pó de rocha fonolito associado à inoculação com bactérias solubilizadoras de potássio (BSK) na cultura do feijoeiro. O experimento foi realizado em vasos até a época do florescimento utilizando o delineamento em blocos casualizados em esquema fatorial 5 (3 doses de fonolito, tratamento com $\mathrm{KCl}$ e controle) x 4 (três estirpes de BSK e o tratamento controle). Foram avaliados a matéria seca da parte aérea (MSPA) e da raiz (MSR), número de nódulos (NN) e o K residual no solo. Os tratamentos que utilizaram o fonolito não apresentaram diferença entre si no desenvolvimento vegetal, porém foram superiores quando comparados ao tratamento controle. Na interação doses de fonolito e inoculação, a estirpe UNIFENAS 100-94 se destacou nas doses $50 \%$ e $100 \%$ semelhante ao tratamento em que foi utilizado o $\mathrm{KCl}$. A inoculação promoveu maior desenvolvimento vegetal e teor de $\mathrm{K}$ residual no solo.
\end{abstract}

Palavras-chave: Produção sustentável; Pó de rocha; Microbiologia do solo.

\begin{abstract}
The objective of this study was to analyze the use of phonolite rock powder associated with inoculation with potassium solubilizing bacteria (BSK) in bean crops. The experiment was carried out in pots until flowering time using a randomized block design in a factorial scheme 5 (3 doses of phonolite, $\mathrm{KCl}$ treatment and control) x 4 (three BSK strains and control treatment). Shoot dry matter (MSPA) and root dry matter (MSR), number of nodules (NN) and residual $\mathrm{K}$ in the soil were evaluated. The treatments that used the phonolite did not differ in plant development, but they were superior when compared to the control treatment. In the interaction doses of phonolite and inoculation, the strain UNIFENAS 100-94 stood out at doses 50\% and 100\% similar to the treatment in which $\mathrm{KCl}$ was used. Inoculation promoted greater plant development and residual $\mathrm{K}$ content in the soil.
\end{abstract}

Keywords: Sustainable production; Rock dust; Soil microbiology.

\section{Resumen}

El objetivo de este estudio fue analizar el uso de polvo de roca de fonolita asociado a la inoculación con bacterias solubilizadoras de potasio (BSK) en cultivos de frijol. El experimento se realizó en macetas hasta el momento de la floración utilizando un diseño de bloques al azar en esquema factorial 5 ( 3 dosis de fonolita, tratamiento $\mathrm{KCl}$ y testigo) x 4 (tres cepas BSK y tratamiento testigo). Se evaluó materia seca aérea (MSPA), materia seca radical (MSR), número de nódulos (NN) y K residual en el suelo. Los tratamientos que utilizaron la fonolita no difirieron en el desarrollo de las plantas, pero fueron superiores al tratamiento testigo. En la interacción dosis de fonolita e inoculación se destacó la cepa UNIFENAS 100-94 a dosis 50\% y 100\% similar al tratamiento en el que se utilizó KCl. La inoculación promovió un mayor desarrollo de las plantas y contenido de $\mathrm{K}$ residual en el suelo.

Palabras clave: Producción sostenible; Polvo de roca; Microbiología del suelo.

\section{Introdução}

O feijoeiro (Phaseolus vulgaris L.) constitui-se em uma importante fonte de proteína nos países em desenvolvimento.

No Brasil, os principais produtores são os estados do Paraná, Minas Gerais, Goiás, São Paulo e Bahia. No entanto, observa-se o cultivo em todas as regiões do país, porém, com menor produtividade, devido principalmente às condições edafoclimáticas (Hiolanda et al., 2018). 
Em relação à fertilidade do solo, o potássio (K) é o segundo elemento mais extraído pela cultura (Malavolta, 2006), sendo que a deficiência deste pode limitar a produtividade do feijoeiro (Oliveira et al., 1996). O K participa como ativador enzimático de diversas reações bioquímicas que ocorrem na planta, do metabolismo de carboidratos e dos mecanismos de abertura e fechamento dos estômatos (Malavolta, 2006).

O cloreto de potássio $(\mathrm{KCl})$ é a fonte mais utilizada, devido principalmente a alta solubilidade. No entanto, o Brasil apresenta alta dependência externa, importando cerca de 90\% do K utilizado na agricultura (ANDA, 2021; Viana et al., 2021). Dessa forma, verifica-se a necessidade de pesquisas visando identificar fontes alternativas de fertilizantes potássicos, conforme observado nos estudos realizados por Ferreira et al. (2009) e Ratke et al. (2020). Ferreira et al (2009), utilizando, respectivamente flogopitito e granito na cultura do feijoeiro. No entanto, esses autores não encontraram resultados satisfatórios no desenvolvimento da planta, provavelmente devido à lenta liberação de $\mathrm{K}$ presente nos minerais destas rochas.

$\mathrm{O}$ fonolito é uma rocha ígnea que contém de 8 a $12 \%$ de $\mathrm{K}_{2} \mathrm{O}$ a depender de sua origem, sendo uma fonte alternativa de potássio às culturas), a forma predominante de $\mathrm{K}$ está retido por ligações covalentes na rede cristalina do mineral, composta, principalmente por microclina $\left(\mathrm{KAISi}_{3} \mathrm{O}_{8}\right)$, ortoclásio $\left(\mathrm{KAISi}_{3} \mathrm{O}_{8}\right)$, andesina $\left[(\mathrm{Na}, \mathrm{Ca})(\mathrm{Si}, \mathrm{Al})_{4} \mathrm{O}_{8}\right]$ e nefelina $\left[(\mathrm{Na}, \mathrm{K}) \mathrm{AlSiO}_{4}\right]$ (Teixeira et al., 2012). Estudos realizados com esse pó de rocha demonstram que este pode ser utilizado em substituição do $\mathrm{KCl}$, quando aplicado na mesma proporção para a cultura do cafeeiro (Mancuso et al., 2014). Para culturas de ciclo curto, como o feijão, não foram encontrados trabalhos utilizando o fonolito como fonte de $\mathrm{K}$.

Esse pó de rocha é considerado de liberação lenta, no entanto pesquisas desenvolvidas em condições axênicas demonstraram o potencial da espécie fúngica Aspergillus niger (Brandão et al., 2014) e de algumas estirpes bacterianas diazotróficas (Florentino et al., 2017) em aumentar a disponibilidade de K na solução por meio da solubilização deste dos minerais. Nesse último estudo, os resultados indicam que a inoculação da estirpe UNIFENAS 100-94 associada ao fonolito, aumentou aproximadamente 12 vezes a concentração de $\mathrm{K}$ no meio de cultura.

Diante desses dados, a associação de microrganismos com o pó de rocha fonolito promoveria uma maior liberação do $\mathrm{K}$, contribuindo para o crescimento vegetal e viabilizando o uso deste produto para culturas de ciclo curto. Dessa forma, os objetivos deste trabalho foram analisar o potencial de uso do pó de rocha fonolito para a cultura do feijoeiro associado à inoculação com estirpes bacterianas solubilizadoras de potássio (BSK).

\section{Metodologia}

\subsection{Cultivo Das Estirpes Bacterianas}

Foram utilizadas três estirpes bacterianas da coleção de Microrganismos do Laboratório de Microbiologia Agrícola da Universidade José do Rosário Vellano - UNIFENAS - Alfenas MG, Brasil. Essas estirpes foram selecionadas por apresentarem alta capacidade em solubilizar potássio do pó de rocha fonolito in vitro (Florentino et al., 2017). Na tabela 1, encontra-se a identificação e características morfológicas e fisiológicas (capacidade de solubilizar fósforo e potássio e produzir AIA) dessas estirpes. 
Tabela 1. Identificação, meio de cultura utilizado para isolamento, características morfológicas e fisiológicas das estirpes bacterianas cultivadas em meio de cultura contendo azul de bromotimol como indicador de $\mathrm{pH}$.

\begin{tabular}{|c|c|c|c|c|c|c|c|}
\hline \multirow{2}{*}{ Estirpes } & \multirow{2}{*}{$\begin{array}{l}\text { Isolamento - } \\
\text { Meio de } \\
\text { cultura }\end{array}$} & \multicolumn{3}{|c|}{$\begin{array}{c}\text { Características morfológicas nos meios de } \\
\text { origem }\end{array}$} & \multicolumn{2}{|c|}{ Solubilização } & \multirow{2}{*}{ Produção AIA ${ }^{2}$} \\
\hline & & $\mathrm{pH}$ & Cor & $\mathrm{EPS}^{1}$ & Fósforo & Potássio & \\
\hline UNIFENAS 100-01 & $\mathrm{JNFb}$ & Ácido & Amarela & Baixa & $+^{3}$ & + & - \\
\hline UNIFENAS 100-21 & $\mathrm{JNFb}$ & Ácido & Amarela & Média & -4 & + & + \\
\hline UNIFENAS 100-94 & JMV & Ácido & Creme & Baixa & - & + & + \\
\hline
\end{tabular}

${ }^{1}$ EPS - produção de exopolissacarídeos; ${ }^{2}$ Ácido 3 -indol-acético; ${ }^{3}$ Positivo; ${ }^{4}$ Negativo. Fonte: Autores.

Para a inoculação no feijoeiro, estas estirpes foram cultivadas em seus respectivos meios de cultura de origem (tabela 1) contendo azul de bromotimol até o aparecimento de colônias isoladas. Essas foram transferidas para o meio líquido, em que foram cultivadas por três dias, até a fase log de crescimento (contendo aproximadamente $10^{9}$ células $\mathrm{mL}^{-1}$ ).

\subsection{Inoculação e Cultivo do Feijão}

$\mathrm{O}$ experimento foi conduzido no setor de Agronomia da UNIFENAS em vasos com capacidade de $10 \mathrm{dm}^{3}$. O solo apresentou a seguinte caracterização química (Embrapa, 2017): $\mathrm{pH}\left(\mathrm{H}_{2} \mathrm{O}\right)=5,5 ; \mathrm{P}=2 \mathrm{mg} \mathrm{dm}^{-3} ; \mathrm{K}^{+}=36 \mathrm{mg} \mathrm{dm}^{-3} ; \mathrm{Ca}^{2+}=0,4$ $\mathrm{cmol}_{\mathrm{c}} \mathrm{dm}^{-3} ; \mathrm{Mg}^{2+}=0,2 \mathrm{cmol}_{\mathrm{c}} \mathrm{dm}^{-3} ; \mathrm{Al}^{3+}=0,1 \mathrm{cmol}_{\mathrm{c}} \mathrm{dm}^{-3} ; \mathrm{H}+\mathrm{Al}=2,1 \mathrm{cmol}_{\mathrm{c}} \mathrm{dm}^{-3} ;$ soma de bases $(\mathrm{SB})=0,7 \mathrm{cmol}_{\mathrm{c}} \mathrm{dm}^{-3} ; \mathrm{CTC}$ potencial $=2,8 \mathrm{cmol}_{\mathrm{c}} \mathrm{dm}^{-3}$; saturação por bases $(\mathrm{V} \%)=25,0$; saturação por alumínio $(\mathrm{m} \%)=13$ e matéria orgânica $(\mathrm{M} . \mathrm{O}$. $)=4$ $\mathrm{g} \mathrm{kg}^{-1}$.

Foi realizada correção do solo com calcário dolomítico $($ PRNT $=90 \%)$ de acordo com o método da elevação por saturação de bases para 60\% (Fageria \& Baligar, 2005). O solo foi umedecido e incubado por 30 dias para o calcário reagir. Posteriormente, foi realizada a adubação de plantio de acordo com o nível tecnológico 3, proposto por Ribeiro et al (1999). Para o potássio, considerando esse nível tecnológico, a recomendação é de $40 \mathrm{Kg}^{-1} \mathrm{ha}^{-1} \mathrm{~K}_{2} \mathrm{O}$. A partir desse valor, foram definidos os tratamentos, constituídos por diferentes doses do pó de rocha fonolito: 1,25; 2,50 e $3,75 \mathrm{~g} \mathrm{vaso}^{-1}$, equivalendo a 50,100 e $150 \%$, respectivamente, da dose recomendada de $\mathrm{K}_{2} \mathrm{O}$. Além dos tratamentos contendo fonolito como fonte de $\mathrm{K}$, foi utilizado um tratamento controle com $0,35 \mathrm{~g}^{\text {vaso }^{-1}}$ de $\mathrm{KCl}\left(100 \%\right.$ da dose recomendada de $\left.\mathrm{K}_{2} \mathrm{O}\right)$. A adubação potássica e fosfatada foi realizada três dias antes do plantio, os quais foram incorporados ao solo, e a adubação nitrogenada foi realizada três dias após a emergência das sementes.

O delineamento utilizado foi o inteiramente casualizado em esquema fatorial ( 5 x 3), sendo três doses de Ekosil (1,25, 2,50 e 3,75 $\mathrm{g} \mathrm{vaso}^{-1}$, equivalendo, respectivamente a 50, 100 e $150 \%$ da dose de $\mathrm{K}_{2} \mathrm{O}$ recomendada), controle sem utilização de potássio e uso do KCl, associadas ou não à inoculação com as três estirpes de BDSK (UNIFENAS 100-01, 100-21 e 100-94).

Foram semeadas quatro sementes por vaso do feijão comum (Phaseolus vulgaris L.) cv. Pérola, onde inoculou-se $5 \mathrm{~mL}$ de suspensão bacteriana em cada semente. Depois de germinadas, foi realizado o desbaste, deixando-se duas plantas, as quais foram conduzidas até o período de florescimento, cerca de 60 dias após o plantio. Nessa época foram avaliados os valores de matéria seca da parte aérea (MSPA) e das raízes (MSR). 
Após a retirada das plantas, foram coletadas amostras de solos para determinação do teor de potássio residual (K residual) no solo, utilizando o extrator Mehlich-1 (Tedesco et al., 1995).

Os dados foram submetidos à análise de variância, e as médias das quatro repetições foram comparadas pelo teste de Scott-Knott, a 5\% de probabilidade, utilizando-se o programa Sisvar (Ferreira, 2014).

\section{Resultados e Discussão}

Para os dados de matéria seca da parte aérea (MSPA) e K residual no solo, a interação fontes de K versus inoculação com as estirpes bacterianas solubilizadoras de potássio (BSK) não foi significativa. Na tabela 1 estão apresentados o efeito das diferentes fontes de $\mathrm{K}$ nos valores de MSPA e K residual no solo.

Avaliando os parâmetros apresentados na tabela 2, em relação à MSPA, nota-se que a adubação com $\mathrm{KCl}$ promoveu maior desenvolvimento vegetal, o que pode ser atribuído à sua alta solubilidade. Já as diferentes doses de fonolito não proporcionaram diferença no desenvolvimento vegetal quando comparadas entre si. No entanto, verifica-se que estas contribuíram para promover um maior desenvolvimento da parte aérea quando comparados ao tratamento em que não foi adicionado potássio (tratamento controle) (Tabela 2).

Tabela 2. Peso da matéria seca da parte aérea (MSPA) e valor de K residual no solo após o cultivo do feijoeiro cultivado com as diferentes fontes e doses de potássio.

\begin{tabular}{lcc}
\hline Tratamentos & MSPA $(\mathrm{g})$ & $\mathrm{K}$ solo $\left(\mathrm{mg} \mathrm{dm}^{-3}\right)$ \\
\hline Controle & $6,20 \mathrm{c}$ & $29,50 \mathrm{e}$ \\
$\mathrm{KCl}$ & $12,17 \mathrm{a}$ & $47,15 \mathrm{~d}$ \\
50 fon & $9,68 \mathrm{~b}$ & $63,30 \mathrm{c}$ \\
100 fon & $9,48 \mathrm{~b}$ & $93,21 \mathrm{~b}$ \\
150 fon & $9,06 \mathrm{~b}$ & $108,58 \mathrm{a}$ \\
\hline
\end{tabular}

Médias seguidas de mesma letra, maiúscula na coluna, não diferem entre si a 5\% de probabilidade pelo teste de Scott-Knott. Fonte: Autores

Ferreira et al. (2009), verificaram que o uso do pó de basalto não contribui para o aumento da produção do feijoeiro. No presente estudo, observa-se que o fonolito promoveu desenvolvimento vegetal de aproximadamente 30\%, quando comparado ao tratamento controle, sem uso de fertilizante potássico.

Em relação ao K no solo, verifica-se que a aplicação de doses crescentes de fonolito relacionaram-se diretamente com maiores valores de $\mathrm{K}$ no solo. Dessa maneira o uso da fonte alternativa de $\mathrm{K}$ é sem dúvida benéfica quando se refere ao $\mathrm{K}$ residual.

Não foram encontrados nódulos em nenhum dos tratamentos, o que pode ser devido à alta disponibilidade de nitrogênio no solo, uma vez que este foi utilizado no plantio, de acordo com a recomendação de Ribeiro et al (1999). É importante considerar ainda o teor de matéria orgânica no solo, que, associado ao $\mathrm{N}$ mineral pode ter limitado a nodulação das plantas, concordando com os resultados observados por Pelegrin et al (2009). Torna-se relevante ressaltar também que as bactérias diazotróficas inoculadas foram isoladas de Brachiaria brizantha, sendo, portanto fixadoras de $\mathrm{N}_{2}$, mas não possuem a capacidade de estabelecer simbiose. Dessa forma, a nodulação era esperada pelas bactérias nativas do solo. 
Para o parâmetro de matéria seca da raiz (MSR), dados apresentados na tabela 3, a dose intermediária de fonolito (100\%) foi semelhante com o tratamento aplicação de $\mathrm{KCl}$ e superior quanto a não aplicação do fonolito, isso indica que tal dose pode ser a ideal em tais condições.

A estirpe UNIFENAS 100-01 proporcionou maiores valores de matéria seca da raíz quando fornecida a dose de $150 \%$ de fonolito e foi semelhante a aplicação de cloreto de potássio.

$\mathrm{Na}$ interação doses de fonolito e inoculação a estirpe UNIFENAS 100-94 se destacou nas doses 50\% e $100 \%$ semelhante ao resultado obtido quando a fonte usada foi cloreto de potássio. Tal observação evidencia a capacidade que essa estirpe possui em solubilizar potássio até mesmo em menores doses da fonte usada e o mais importante, que é fornecer potássio na mesma proporção que o cloreto de potássio.

Tabela 3. Valores de matéria seca da raiz (g) (MSR) obtidos após o cultivo do feijoeiro com diferentes doses de fonolito, associados ou não à inoculação com diferentes estirpes bacterianas.

\begin{tabular}{|c|c|c|c|c|}
\hline \multirow{2}{*}{ Fontes K } & \multicolumn{4}{|c|}{ Inoculação } \\
\hline & Controle & 100-01 & $100-21$ & $100-94$ \\
\hline Controle & $1,14 \mathrm{~B} \mathrm{a}$ & $1,09 \mathrm{~B} \mathrm{a}$ & $1,20 \mathrm{~B} \mathrm{a}$ & $1,26 \mathrm{~B} \mathrm{a}$ \\
\hline $\mathrm{KCl}$ & $1,69 \mathrm{~A} \mathrm{a}$ & $1,74 \mathrm{~A} \mathrm{a}$ & $1,97 \mathrm{~A} \mathrm{a}$ & $1,93 \mathrm{~A} \mathrm{a}$ \\
\hline 50 fon & $1,19 \mathrm{~B} \mathrm{~b}$ & $1,23 \mathrm{~B} \mathrm{~b}$ & $1,16 \mathrm{~B} \mathrm{~b}$ & $1,93 \mathrm{~A} \mathrm{a}$ \\
\hline 100 fon & $2,05 \mathrm{~A} \mathrm{a}$ & $1,11 \mathrm{~B} \mathrm{~b}$ & $0,87 \mathrm{~B} \mathrm{~b}$ & $1,59 \mathrm{~A} \mathrm{a}$ \\
\hline 150 fon & $1,52 \mathrm{~B} \mathrm{~b}$ & $2,15 \mathrm{~A} \mathrm{a}$ & $0,88 \mathrm{~B} \mathrm{c}$ & $0,62 \mathrm{C} \mathrm{c}$ \\
\hline
\end{tabular}

Médias seguidas de letras distintas, maiúsculas na coluna e minúsculas na linha, diferem entre si pelo teste de Scott Knott a 5\% de probabilidade. Fonte: Autores

A maior dose de fonolito interferiu negativamente no desenvolvimento da raiz. Considerando que o fonolito possui $\mathrm{K}$ e este em excesso pode interferir negativamente no desenvolvimento da planta, Prazeres et al. (2015) em trabalho com feijãocaupi observou esses efeitos negativos quando aumentou as doses de K, provavelmente pela intensificação dos efeitos osmóticos na planta. Outra hipótese é que $\mathrm{K}$ em dosagens mais altas pode diminuir absorção de Ca e Mg sendo prejudicial no desenvolvimento da planta (Malavolta, 2006).

Atualmente fala-se muito em bioprospeção, que pode ser definida como a procura por organismos ou partes deles, como genes, enzimas, compostos e processos, chamados coletivamente recursos genéticos, que possuam potencial econômico e que possam levar ao desenvolvimento de um produto (Saccaro Junior, 2011). Segundo Ramos (2016) a identificação e seleção de microrganismos pode se tornar uma alternativa sustentável na atividade agrícola, indústria alimentícia, farmacêutica, química, têxtil, e biotecnológica, em um mercado que se expande de maneira global. Também conhecida como prospecção essa linha de pesquisa vem se expandindo de forma que instituições de pesquisa buscam cada vez mais alternativas de aderirem a nova técnica.

Na literatura são encontrados estudos sobre a capacidade de algumas espécies microbianas em solubilizar minerais contendo potássio (Alves et al., 2010), favorecendo o crescimento das plantas. Nestes estudos, os autores consideram que a produção de ácidos orgânicos constitui-se num dos principais mecanismos utilizados por estes microrganismos (Meena et al., 2014).

O uso de microrganismos é uma alternativa para a redução de impactos ambientais e diminuição de custos de produção na agropecuária, e nesse sentido é necessário conhecer como estes se desempenham associados á culturas em diferentes situações de manejo. A associação das bactérias com diferentes doses de fontes que também são alternativas é uma forma identificar as estirpes que se destacam em tais situações. 
Em trabalho com Biossolubilização de potássio in vitro a partir da rocha fonolito por microrganismos do solo Silva et al (2015) obteve acréscimo de 70\% no teor de K no meio de cultura após 10 dias de incubação através da estirpe B30 foi identificada como pertencente ao gênero Burkholderia sp. Tais resultados evidenciam a capacidade desses microrganismos em solubilizar K, proporcionando melhores resultados quando associados a aplicação do pó de rocha fonolito.

\section{Conclusão}

$\mathrm{O}$ uso do fonolito contribuiu significativamente promovendo aumento do teor de $\mathrm{K}$ residual no solo e associado a inoculação promoveu melhores resultados no desenvolvimento vegetal.

Estudos posteriores são necessários visando avaliar o teor de K na planta e visando avaliar o desempenho das estirpes bacterianas em diferentes condições de clima e em outras espécies vegetais.

\section{Agradecimentos}

Os autores agradecem o apoio financeiro da FAPEMIG.

\section{Referências}

ANDA. Associação Nacional para Difusão de Adubos. Relatório sobre o Mercado de Fertilizantes. http://anda.org.br/pesquisa_setorial/

Alves, L., Oliveira, V. L. \& Filho, G N S. (2010). Utilization of rocks and ectomycorrhizal fungi to promote growth of eucalypt. Brazilian Journal Microbiology, 41(1), 676-684.

Brandão, J. A. V., Lopes-Assad, M. L. R. C. \& Ceccato-Antonini, S. R. (2014). Solubilização de pós de diabásio e de fonolito por fungo filamentoso. Ceres, $61(5), 740-745$

Empresa Brasileira De Pesquisa Agropecuária - EMBRAPA. (2017). Manual de métodos de análise de solos. 3.ed. rev. Embrapa Solos: Rio de Janeiro. 577 p.

Fageria, N. K. \& Baligar, V. C. (2005). Enhancing nitrogen use efficiency in crop plants. Advances in agronomy, 88(1), 97-185.

Ferreira, E. R. N. C., Almeida, J. A. \& Mafra, A. F. (2009). Pó de basalto, desenvolvimento e nutrição do feijão comum (Phaseolus vulgaris) e propriedades químicas de um Cambissolo Húmico. Revista de Ciências Agroveterinárias, 8(2), 111-121.

Ferreira, D. F. (2014). Sisvar: A computer statistical analysis system. Ciência e Agrotecnologia, 35(6), 1039-1042.

Florentino, L. A., Rezende, A. V., Miranda, C. C. B., Mesquita, A. C., Mantovani, J. R. \& Bianchini, H. C. (2017). Potassium solubilization in phonolite rock by diazotrophic bacteria. Comunicata Scientiae, 8(1), 17-23.

Hiolanda, R., Machado, D. H., Candido, W. J., Faria, L. C. \& Dalchiavon, F. C. (2018). Desempenho de genótipos de feijão carioca no Cerrado Central do Brasil. Revista de Ciências Agrárias, 41(3), 815-824.

Malavolta, E. (2006). Manual de nutrição Mineral de Plantas. São Paulo: Editora Agronômica Ceres, 638p.

Mancuso, M. A. C., Soratto, R. P., Crusciol, C. A. C. \& Castro, G. S. A. (2014). Effect of potassium sources and rates on Arabica coffee yield, nutrition, and macronutrient export. Revista Brasileira de Ciência do Solo, 38(5), 1448-1456.

Meena, V. S., Maurya, B. R. \& Verma, J. P. (2014). Does a rhizospheric microorganism enhance $\mathrm{K}^{+}$availability inagricultural soils? Microbiological Research, 169(5), 337-347.

Oliveira, I. P., Araujo, R. S. \& Dutra, L. G. (1996) Nutrição mineral e fixação biológica de nitrogênio. In: Araújo, R. S., Rava, C., Stone, L. F. \& Zimmermann, M. J. O. Cultura do feijoeiro comum no Brasil. Piracicaba: Potafos, p. 169-221.

Pelegrin, R., Mercante, F. M., Otsubo, I. M. N. \& Otsubo, A. A. (2009). Resposta da cultura do feijoeiro à adubação nitrogenada e à inoculação com rizóbio. Revista Brasileira de Ciência do Solo, 33(1):219-226.

Prazeres, S. S., Lacerda, C. F., Barborsa, F. E. L., Amorim, A. V., Araújo, I. C. S. \& Cavalcante, L. F. (2015). Crescimento e trocas gasosas de plantas de feijão-caupi sob irrigação salina e doses de potássio. Revista Agro@ mbiente On-line, 9(2), 111-118.

Ramos, T. C. A. A. (2016). Identificação e caracterização genética para prospecção do potencial biotecnológico de fungos filamentosos isolados de solos do Quadrilátero Ferrífero, MG. 2016. 94 p. Dissertação (mestrado) - Universidade Federal de São João Del-Rei, Programa de Pós-Graduação em Ciências Agrárias. Sete Lagoas, MG.

Ratke, R. F., Andrade, T. G., Rocha, S. G., Sousa, A., Dai, P. V. S., Silva-Filho, E. C., Bertolino, L. C., Zuffo, A. M., Oliveira, A. M. \& Aguilera, J. G. (2020). Regional rock dust as a source of phosphorus and potassium for plants. Research, Society and Development, 9 (7), e497974257. 
Research, Society and Development, v. 10, n. 2, e53711226248, 2022

(CC BY 4.0) | ISSN 2525-3409 | DOI: http://dx.doi.org/10.33448/rsd-v10i2.26248

Ribeiro, A. C.; Guimarãez, P. T. \& Alvarez, V. H. (1999). Recomendações para o uso de corretivos e fertilizantes em Minas Gerais - $5^{a}$ Aproximação. Editora Viçosa, Minas Gerais, 359 p.

Saccaro Junior, N. L. (2011). Desafios da bioprospecção no Brasil. Texto para Discussão, Instituto de Pesquisa Econômica Aplicada (IPEA). 38 p.

Silva, U. C., Marriel, I. E., Paiva, C. A. O.; Gomes, E. A., Resende, A. V. \& Lana, U. G. P. (2015). Biossolubilização de Potássio In Vitro a Partir da Rocha Fonolito por Microrganismos do Solo. Documentos EMBRAPA, $28 \mathrm{p}$.

Tedesco, M. J., Volkweiss, S. J. \& Bohnen, H. (1995). Análises de solo, plantas e outros materiais. 2.ed. Porto Alegre, Universidade Federal do Rio Grande do Sul, 174 p. (Boletim técnico, 5).

Teixeira, A. M. S., Sampaio, J. A., Garrido, F. M. S \& Medeiros, M. E. (2012). Avaliação da rocha fonolito como fertilizante alternativo de potássio. Holos, $5(1), 21-33$

Viana, L. S. B.; Caitano, T. B. S.; Pontes, A. N. (2021). Soil remineralization as an initiative for sustainable development . Research, Society and Development, 10(4), e45101421516. 